\title{
Characterization of IS2112, a new insertion sequence from Rhodococcus, and its relationship with mobile elements belonging to the IS110 family
}

\author{
Leonid A. Kulakov, ${ }^{1}$ Gerrit J. Poelarends, ${ }^{2}$ Dick B. Janssen ${ }^{2}$ \\ and Michael J. Larkin ${ }^{1}$
}

Author for correspondence: Leonid A. Kulakov. Tel: +441232 335577. Fax: +441232661462. e-mail: 1.kulakov@queens-belfast.ac.uk

\footnotetext{
1 The Questor Centre, David Keir Building, The Queen's University of Belfast, Belfast BT9 5AG, UK; and School of Biology and Biochemistry, Medical Biology Centre, The Queen's University of Belfast, Belfast BT9 7BL, UK

2 Department of Biochemistry, Groningen Biomolecular Sciences and Biotechnology Institute, University of Groningen, Nijenborgh 4, 9747 AG Groningen, The Netherlands
}

\begin{abstract}
A new insertion sequence (IS2112) was identified in the genome of the 1haloalkane-utilizing bacterium Rhodococcus rhodochrous NCIMB 13064. The insertion element is 1415 bp long, does not contain terminal inverted repeats, and is not flanked by directly repeated sequences. IS2112 belongs to the IS110 family of transposable elements, and forms a separate subfamily, along with IS116. Two copies of IS2112 were found in R. rhodochrous NCIMB 13064 and one, two or three copies of a similar sequence were detected in five other 1 haloalkane-degrading Rhodococcus strains. There were no sequences homologous to IS2112 found in the 1-haloalkane-degrading 'Pseudomonas pavonaceae' 170 and Rhodococcus sp. HA1 or in several Rhodococcus strains which do not utilize haloalkanes. IS2112 was originally found in plasmid PRTL1 of $R$. rhodochrous NCIMB 13064, which harbours genes encoding utilization of 1-haloalkanes, and was located $5 \mathrm{kbp}$ upstream of the haloalkane dehalogenase gene (dhaA). Although the second copy of IS2112 in strain NCIMB 13064 was also present on the pRTL1 plasmid, these sequences do not apparently comprise a single composite transposon encoding haloalkane utilization. An analysis of derivatives of NCIMB 13064 revealed that IS2112 was involved in genome rearrangements. IS2112 appeared to change its location as a result of transposition and as a result of other rearrangements of the NCIMB 13064 genome.
\end{abstract}

Keywords: Rhodococcus, genome rearrangements, insertion element, haloalkane dehalogenase

\section{INTRODUCTION}

The genus Rbodococcus includes a diverse group of Gram-positive bacteria which are noted for their ubiquity and remarkable ability to degrade a wide variety of xenobiotics, including aliphatic and aromatic compounds. Although there have been some studies related to the genetics of rhodococci, the means by which they acquire biodegradation pathways have not been investigated. However, it is clear that in other bacteria mobile DNA elements can contribute to the acquisition of biodegradation pathways by promoting mutations and

The GenBank accession number for the sequence reported in this paper is AF017179. genomic rearrangements in the chromosome and in transmissible plasmids. Few transposable elements have been identified in Rhodococcus species: the nucleotide sequences of IS1166 and IS1295 were determined (Denome \& Young, 1995; Jager et al., 1995) and were shown to be very similar to Mycobacterium smegmatis IS6120 (Guilhot et al., 1992) and Staphylococcus aureus IS256 (Rouch et al., 1987) insertion sequences. Recently IS1415, belonging to the IS21 family, was identified in Rhodococcus erythropolis and its transposition in the bacterial genome was demonstrated (Nagy et al., 1997).

Rhodococcus rhodochrous NCIMB 13064 degrades 1chloroalkanes by means of a haloalkane dehalogenase (DhaA) that was shown to be encoded on a $100 \mathrm{kbp}$ plasmid designated pRTL1 (Kulakova et al., 1995). A 
number of dehalogenase-negative derivatives of this strain were isolated. These mutants showed rearrangements in both the chromosome and plasmid pRTL1. (Kulakova et al., 1995, 1997). Some of the derivatives were able to revert to the original phenotype (Kulakova et al., 1995), suggesting the occurrence of reversible genetic rearrangements and a possible role for a transposon or an insertion element.

In this paper, we describe the presence of a DNA segment proximal of the haloalkane dehalogenase gene that shows sequence similarity to some transposable elements found in actinomycetes. The distribution of the corresponding transposable element and its role in genetic rearrangements are discussed.

\section{METHODS}

Bacterial strains and plasmids. Escherichia coli strain DH5 $\alpha$ (Sambrook et al., 1989) and plasmid vectors pUC129 (Keen et al., 1988) and pBluescript $\mathrm{KS}(+)$ (Stratagene) were used for the cloning experiments. $R$. rhodochrous NCIMB 13064 (Curragh et al., 1994), R. erythropolis NCIMB 13065 and Rhodococcus strains Acr33, I1 and A1 (Kulakov et al., 1998) were described previously. Of these strains, only NCIMB 13064 and NCIMB 13065 were haloalkane degraders and carried the $d h a A$ gene, which encodes haloalkane dehalogenase. The haloalkane-degrading Rhodococcus strains GJ70 (Janssen et al., 1987), HA1 (Scholtz et al., 1987), m15-3 (Yokota et al., 1986), Y2 (Sallis et al., 1990) and TB2 (collection of Department of Biochemistry, Groningen Biomolecular Sciences and Biotechnology Institute) and 'Pseudomonas pavonaceae' 170 (Verhagen et al., 1995) were used for the analysis of the distribution of IS2112. All Rbodococcus strains as well as ' $P$. pavonaceae' 170 were classified on the basis of $16 \mathrm{~S}$ rRNA gene sequence analysis (unpublished results). Derivatives of $R$. rhodochrous NCIMB 13064 were described previously (Kulakova et al., 1995) as well as obtained in this work.

Media and growth conditions. Rhodococcus, Pseudomonas and $E$. coli strains were propagated in a rich (2YT or NB) or minimal (M9) medium (Miller, 1972). When required, Difco Bacto agar $(1.8 \%, \mathrm{w} / \mathrm{v})$ was added to the medium. Ampicillin $\left(100 \mu \mathrm{g} \mathrm{ml}^{-1}\right)$, tetracycline $\left(15 \mu \mathrm{g} \mathrm{ml}^{-1}\right)$, IPTG $\left(50 \mu \mathrm{g} \mathrm{ml}^{-1}\right)$ and $\mathrm{X}-\mathrm{Gal}\left(50 \mu \mathrm{g} \mathrm{ml}^{-1}\right)$ were used for the detection of recombinant plasmids.

DNA techniques. Total DNA from $R$ bodococcus strains was isolated as described by Kulakova et al. (1995). Recombinant DNA work was done by using standard protocols as described by Sambrook et al. (1989). Restriction of both total DNA and recombinant plasmids was performed using enzymes obtained from Pharmacia, according to the manufacturer's instructions. The Sephaglas BandPrep kit (Pharmacia) was used for the recovery of restriction fragments and PCR products from agarose gels.

DNA fragments were transferred to Hybond-N + membrane (Amersham) or to a positively charged nylon membrane (Boehringer) by Southern blotting, as described by Sambrook et al. (1989). The membranes were then treated according to the instructions of the manufacturer. Hybridization probes were labelled using the Gene Images Random Prime Labelling Module (Amersham) or the digoxigenin-dUTP DNA Labelling and Detection kit (Boehringer). Hybridization was carried out at $64{ }^{\circ} \mathrm{C}$ and detection was performed according to the manufacturer's instructions.
DNA sequencing and analysis. Plasmids pUC129 and pBluescript $\mathrm{KS}(+)$ with inserts containing IS2112 and surrounding regions were used as templates in sequence reactions using the Taq Dye-Deoxy Terminator Cycle Sequencing kit (Applied Biosystems). DNA sequences were obtained using an automatic sequencer (Applied Biosystems, model 373A). The nucleotide sequences of both strands were determined. Sequencing of PCR products was performed after template purification from agarose gels. Primer synthesis was carried out by Dr C. Stevenson (School of Biology and Biochemistry, The Queen's University of Belfast). Editing and initial analysis of the sequences was performed using the DNASIS (Hitachi) software package. Searches for nucleotide and amino acid sequence similarities were done by using the FASTA and BLAST programs (Pearson \& Lipman, 1988) and the EMBL and GenBank databases.

Alignments of the protein sequences were performed using the ClUSTAL w program (Thompson et al., 1994). Phylogenetic analysis of the alignment of amino acid sequences was done using the PHYLIP (version 3.57c) package (Felsenstein, 1997) and the TREECON program (Van de Peer \& De Wachter, 1994). For the PHYLIP analysis, bootstraps were obtained with the SEQBOOT program (100 data sets were generated) and distance matrices were generated with the PROTDIST program (PAM001 matrix) and the DNADIST program. Neighbour-joining was carried out with the NEIGHBOR program using a random input order of sequences. Parsimony analyses were done with the PROTPARS and DNAPARS programs using ordinary parsimony and randomized input order of sequences. For the analyses with the TREECON program, Tajima and Nei correction (Tajima \& Nei, 1984) was used and trees were generated by neighbour-joining.

PCR. Amplification of Rhodococcus sequences was done with Taq + DNA polymerase (Stratagene) in a buffer supplied by the manufacturer. Reactions were carried out in volumes of $25 \mu \mathrm{l}$ or $50 \mu \mathrm{l}$ with dNTPs at $200 \mu \mathrm{M}$ concentrations, primers at $0.15 \mu \mathrm{M}$ each, DNA $-50-100 \mathrm{ng}$ and Taq +0.5 unit per reaction. The following temperature profile was used: denaturation at $95^{\circ} \mathrm{C}$ for $3 \mathrm{~min}$, followed by 30 cycles of $95^{\circ} \mathrm{C}$ for $40 \mathrm{~s}, 60^{\circ} \mathrm{C}$ for $30 \mathrm{~s}$, and $72{ }^{\circ} \mathrm{C}$ for $1 \mathrm{~min}$.

To determine nucleotide sequences adjacent to IS2112 in different derivatives of NCIMB 13064, total DNA was isolated from the corresponding strains and inverse PCR amplifications were carried out as follows. Total DNA $(0.5-1.0 \mu \mathrm{g})$ was digested with either $B a m H I, X b o I$ or EcoRI, ligated with T4 DNA ligase and used in the PCR reactions with different internal, divergent IS2112 primers. The primers were: $5^{\prime}$ GCGCAGATCGGTGAGAC 3' (969-985 bp of the IS2112 sequence, forward primer) and $5^{\prime}$ GCCTCCCACGCAATCTC 3' (843-859 bp, reverse primer) - used with BamHI-, XhoI- or EcoRI-digested DNA; 5' GCGCAGATCGGTGAGAC 3' (969-985 bp, forward primer) and 5' CCCAATGGAGTTCGTCG 3' (359-375 bp, reverse primer) for Bam HI- or EcoRI-digested DNA. PCR products obtained were sequenced as described above.

\section{RESULTS AND DISCUSSION}

\section{Identification and sequence analysis of IS2112}

The $R$. rhodochrous haloalkane dehalogenase gene (dhaA) was characterized previously (Kulakova et al., 1997). A number of direct and inverted repeats were found immediately upstream of the $d h a A$ coding region, and the involvement of these repeats in genomic 


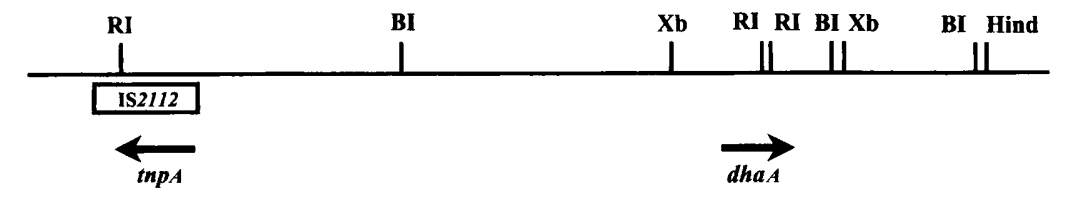

Fig. 1. Schematic representation of the PRTL1 region in the vicinity of IS2112. The position of IS2112 is indicated by a boxed area. $\operatorname{tnp} A$, putative transposase gene of IS2112; dhaA, haloalkane dehalogenase gene (Kulakova et al., 1997). RI, EcoRI; BI, BamHI; Xb, Xbal; Hind, HindIII.
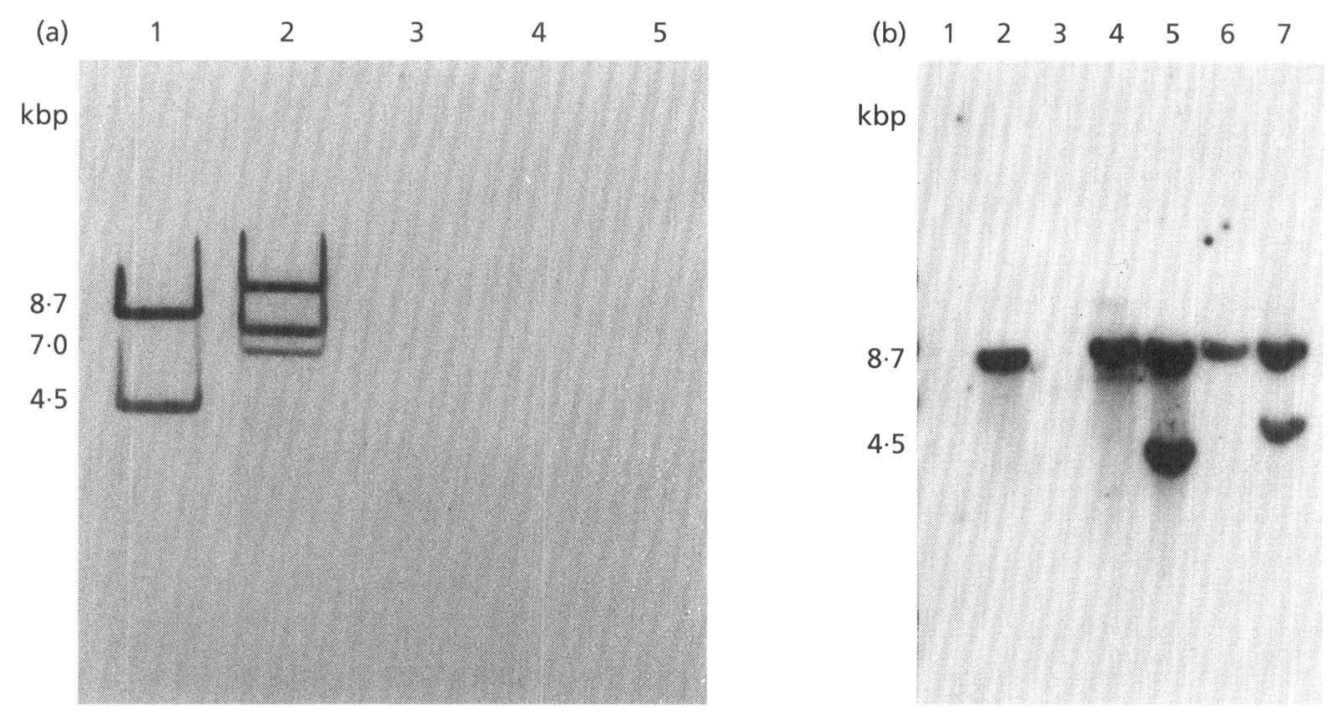

Fig. 2. Southern blot analysis of BamHI-digested total DNA preparations of Rhodococcus strains and ' $P$. pavonaceae' 170. Restriction fragments were separated in a $0.9 \%$ agarose gel and transferred onto a membrane. Hybridization was carried out with a $1050 \mathrm{bp}$ internal Sall fragment of IS2112. (a) Hybridization using the Gene Images kit (Amersham). Lanes: 1, NCIMB 13064; 2, NCIMB 13065; 3, Rhodococcus sp. 11; 4, Rhodococcus sp. Acr33; 5, Rhodococcus sp. A1. (b) Hybridization with the DNA Labelling and Detection kit (Boehringer). Lanes: 1, strain 170; 2, GJ70; 3, HAl; 4, m15-3; 5, NCIMB 13064; 6, Y2; 7 , TB2.

rearrangements associated with mutations that resulted in loss of dehalogenase activity was suggested (Kulakova et al., 1997). In order to further analyse genetic elements which may be involved in such rearrangements of the $R$. rhodochrous genome, overlapping clones covering approximately $40 \mathrm{kbp}$ of plasmid pRTL1, including the dhaA gene, were obtained from the gene bank of NCIMB 13064 (Kulakova et al., 1997) using the cosmid vector PLAFR5.

DNA sequencing of these cosmid clones revealed the presence of an ORF $5 \mathrm{kbp}$ upstream of the $d h a A$ gene transcribed in the opposite direction to the $d h a A$ gene (Fig. 1). This ORF was preceded by a putative ribosomebinding site (Shine \& Dalgarno, 1974) and coded for a putative protein of 400 amino acids with a calculated molecular mass of $43769 \mathrm{Da}$. A search with the FASTA program (Pearson \& Lipman, 1988) in different protein databases revealed that the deduced amino acid sequence was similar to that of transposase ORFs present in mobile elements found in actinomycetes.

No inverted or direct repeats were identified in the vicinity of the analysed ORF, but it is known that some of the transposable elements found in Gram-positive bacteria lack the terminal inverted repeats that are typical of the majority of transposons and also do not duplicate the target site in the genome upon insertion (Leskiw et al., 1990; Hernandez et al., 1994). Accordingly, we concluded that the identified $R$. rhodochrous NCIMB 13064 sequence is an insertion element and we named it IS2112. The exact size and ends of IS2112 were identified on the basis of the analysis of several copies of this element and its integration site (see below).

To identify the number of IS2112 copies present in NCIMB 13064, a 1050 bp SalI DNA fragment comprising almost the entire putative transposase gene of IS2112 was used as a probe in Southern hybridization experiments. Two copies of homologous DNA were detected by this analysis (Fig. 2a). Two BamHI fragments, each containing a copy of IS2112, were cloned from NCIMB 13064 using the pUC129 vector and analysed. The resulting sequences of the putative transposase genes and adjacent regions (197 bp upstream and $15 \mathrm{bp}$ downstream) were very similar, but not identical. The nucleotide substitutions (total of 23) were evenly distributed and in all cases but two affected the third position of the triplets in the coding region. 


\begin{tabular}{|c|c|c|}
\hline IS2112 & MRETHTHAWVGIDAGKGHHWAAVVDEAGI,IVWSHKI INDETAI & 60 \\
\hline IS116 & MSTRHDRIWVGIDAGKGHHWAVAVDADGETLFSTKVINDEAQV & 60 \\
\hline IS 900 & MAQP - VWAGVDAGKADHYCMVINDDAGIRLLSQRVANDEAAL & 60 \\
\hline IS901 & -MAEPDRVWVGIDVGKSTHHACAIDDTGKVVWSKKI PNEQAAI & 60 \\
\hline \multirow[t]{2}{*}{ IS1110 } & MLAGLSVGNMVDDKRIGGSMEADQLWAGADVGKEHHWVCVVDDKGT'AVLSRKLTNDEQPI & \\
\hline & 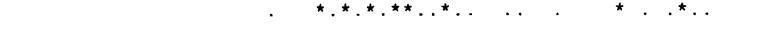 & \\
\hline IS2112 & LHALSEILALAD - ELHWAVDISGTSSTLLLALLAAHDQSAVYVPCRTVNRMSGAYRG-E & 120 \\
\hline IS116 & L-TLIETARERE - -EVRWAVDISGRASTLLLALLLVAHGQNVVYVPCRTVNRMSGAYKG - E & 120 \\
\hline IS 900 & LELIAAVTTLADGGEVTWAIDLNAGGAALL IALLI IAAGQRLLY IPCRTVHHAAGSYRG - E & 120 \\
\hline IS901 & EDLIAQGGRIAN - - HVVWAIDLTSPPAALLIAVLLSAKREVVYVPGRTVNTMSHAFRG-E & 120 \\
\hline \multirow[t]{2}{*}{ IS1110 } & RELIDEIDALGC - -DVSWTVDLTTVYASLLLTVLADAGKSVRYLTGRAVWQASVTYRGGE & 120 \\
\hline & 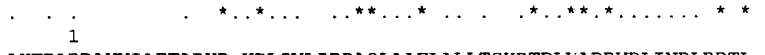 & \\
\hline IS2112 & AKTDARDAYVIAETARHR -HDLSVLI PPAQLAAELALLTSHRTDLVADRVRLINRLRDTL & 180 \\
\hline IS116 & GKTDAKDARVIADQARMR - RDFAPLDRPPELVTTLRLLTNHRADLI ADRVRLINRLRDLL & 180 \\
\hline IS 900 & GKTDAKDAAI IADQARMR - HDLQPLRAGDDIAVELRI ITSRRSDLVADRTRAIEPNARPA & 180 \\
\hline IS901 & GKTDAKDARVIAETARHR - RDLSPVVPGEDLVAELRSLTRYRSDLMADWVRGVNRLRSML & 180 \\
\hline \multirow[t]{2}{*}{ IS1110 } & AKTDAKDARVIADQSRMRGADLPVLHPDDDLITELRMLTAHRADLVADRTRTINRLREQL & 180 \\
\hline & 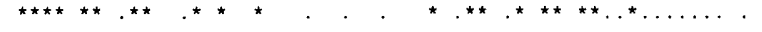 & \\
\hline IS2112 & TGVFPALERAFDFGRHKGALVLLTGFQTPRAIRRRGRTRLSLWLGKRGVR - - GADGVAEI & 240 \\
\hline IS116 & TGICPALERAFDYSAAKGPVVMLTEYQTPAALRRTGVKRLTTWLGRRKVR - -DADTVAAK & 240 \\
\hline IS900 & AGILSALERAFDYNKSRAALI LLTGYQT'PDALRSAGGARVAAFLRKRKAR - -NADTVAAT & \\
\hline IS901 & TAI FPALEAAFDYS - TRAPLILVSAMCTPGE IRSAKRAGVI KHLRKNRAWPNNIDTIADK & \\
\hline \multirow[t]{2}{*}{ IS 1110} & IAVCPALERVAQLTQDRGWVVLLTRYQRPKAIRHSGVSRLTKMLGDAGVR- -NAATIAAA & \\
\hline & 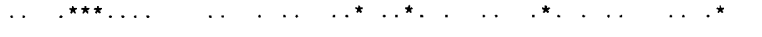 & \\
\hline IS2112 & AWEAASAQNVVLPGEAVAAQLVADIADRVLAVDVQLAR IDAQIGET FRRHPQAAVIESMP & \\
\hline rs116 & AIEAARTQQVVLPGEKRATKL VCDLAHQLLALDER I KDNDRE IRET ?RTDDRAEI IESMP & 300 \\
\hline IS900 & ALQAANAQHSIVPGQQLAATVVARLAKEVMALDTEIGDTDAMIEER RRRHRHAEI ILSMP & 300 \\
\hline IS901 & ALAAAAGQI ITLPGE-EAAAL I KQLAARLLDLDRQI KDIDKQITNK TGEHPSAAI IESMP & 300 \\
\hline \multirow[t]{2}{*}{ IS1110 } & AVTAAKSQTVRLPGEDVAAGLVADLAGEVVALDDR I KSTDADIEDR TRRHPAAEVI TSLP & 30 \\
\hline & 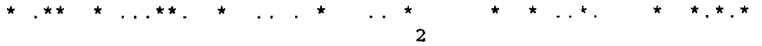 & \\
\hline IS2112 & GIGPILGAEFVVAAG-DMSAYSDAGHLASAAGLVPVPRDSGRRTGN1HRPKRYSRRLRRV & 360 \\
\hline IS116 & GMGPVLGAEFVAIVG-DLSGYKDAGRLASHAGLAPVPRDSGRRTGN $/$ HRPQRYNRRLRWL & 360 \\
\hline IS900 & GFGVILGAEFLAATGGDMAAFASADRIAGVAGLAPVPRDSGRISGNLLKRPRRYDRLLRA & 360 \\
\hline IS901 & GMGPHLGAEFLVITGGNMAAFTNPGRLASFAGLVPVPRDSGRITGNJJHRPKRYNRRLRRV & 360 \\
\hline \multirow[t]{2}{*}{ IS1110 } & GMGFRLGAEFLAAVG -DPTLIGSADQLAAWAGLAPVSRDSGKRTGRI_HTPKRYSRRL_RRV & 360 \\
\hline & 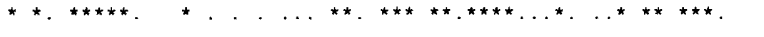 & \\
\hline IS2112 & FYLSAQTS I I KDGPNREFYLQKRSEGMRHVQAVI ALARRQVNVIWAI_LRDDRLF IVDAPA & \\
\hline IS116 & FYMSAQTAMMR PGPSRDYYLKKRGEGLLHTQALLSLARRRVDVLWAMLRDKRLFTPAPPV & 420 \\
\hline IS 900 & CYLSALVSIRTDPSSRTYYDRKRTEGKRHTQAVLALARRRLNVLWAMLRDHAVYHPATTT & \\
\hline IS901 & FYLAALSSLKIEGSSRAFYDRKRSENHIHTQALLALARRHVDVLWAI,LRDNRTWQPQQPT & 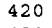 \\
\hline \multirow[t]{2}{*}{ IS1110 } & MYMSALTAIRCDPHSKAYYQRKRDEGKRPI PATLCLARRVPTSFTPSSVTTAPGNPNHPR & \\
\hline & 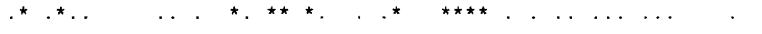 & \\
\hline IS2112 & LRTA & 46 \\
\hline IS116 & TQTA-1, & \\
\hline IS900 & AAA & 46 \\
\hline IS901 & VAAA & 46 \\
\hline IS1110 & SPSRRLDIFIESPFAIYALVSGVGGPAVGAIVLAVVVDDDDDKKAFGGR & \\
\hline
\end{tabular}

Fig. 3. Amino acid sequence alignment of the transposases of IS2112 and related IS elements. Alignment was performed with the CLUSTAL W program. Residues identical in all proteins are indicated by asterisks and those identical in IS2112 and IS116 sequences are indicated by dots. The highly conserved regions 1 and 2 (Hernandez et al., 1994) are indicated by underlining. IS902 transposase, which is very similar to that of IS901, is not presented in this alignment.
Although very closely related to IS2112, this copy may be designated iso-IS2112.

The base composition of IS2112, with a $60.9 \mathrm{~mol} \%$ $\mathrm{G}+\mathrm{C}$ content, was similar to that of a previously analysed region of the pRTL1 plasmid $(60 \mathrm{~mol} \%)$ (Kulakova et al., 1997), but somewhat lower than the 67-72 mol\% typical for Rhodococcus species (Finnerty, 1992) and another $R$. rhodochrous NCIMB 13064 plasmid (Kulakov et al., 1997). The comparatively high $\mathrm{G}+\mathrm{C}$ content of IS2112 was reflected in the preferential use of $\mathrm{C}$ and $\mathrm{G}$ residues at the $5^{\prime}$ ends of the codons of the putative transposase gene. A similar pattern of codon usage was found for the previously characterized dhaA gene (Kulakova et al., 1997). These findings may reflect an association between IS2112 and the conjugative plasmid pRTL1 and its relatively recent occurrence in $R$. rhodochrous NCIMB 13064.

\section{Relatedness of IS2112 to other transposable elements}

Database searches (GenBank and EMBL) revealed that the putative transposase of IS2112 was most closely related to that of IS116 (Leskiw et al., 1990) with $61 \%$ amino acid identity. Significant similarity was also detected with IS1110 (Hernandez et al., 1994) and IS901 (Kunze et al., 1992), both isolated from Mycobacterium avium, and IS 900 from Mycobacterium paratuberculosis (Green et al., 1989). These IS elements comprise a single family based upon similarity of their deduced gene products (Leskiw et al., 1990). All members of this family have a single transposase gene which occupies almost the entire element (Leskiw et al., 1990; Hernandez et al., 1994). A lower level of similarity of IS2112 was found with the Streptomyces mini-circle (Henderson et al., 1989; Lydiate et al., 1986, 1989) and IS110 (Bruton \& Chater, 1987).

An alignment of the amino acid sequences of the transposase genes of IS elements belonging to the IS110 family (Mahillon \& Chandler, 1998), which was previously known as the IS900 family (Hernandez et al., 1994), clearly demonstrates the relatedness between IS2112 and other family members (Fig. 3). Two highly conserved regions noticed earlier (Hernandez et al., 1994) are also present in the IS2112 transposase. These regions, designated 1 and 2 in Fig. 3, are also closely related to sequences within the pilin gene inversion proteins of Moraxella species (Fulks et al., 1990). The 
(a)

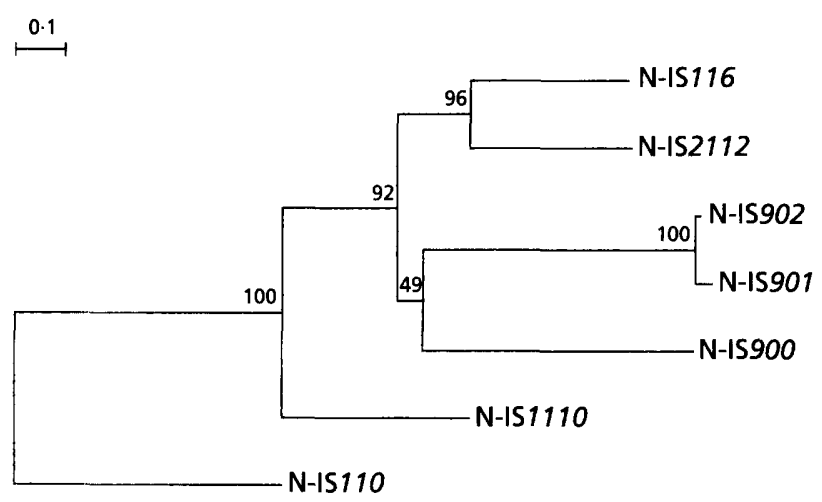

(b)

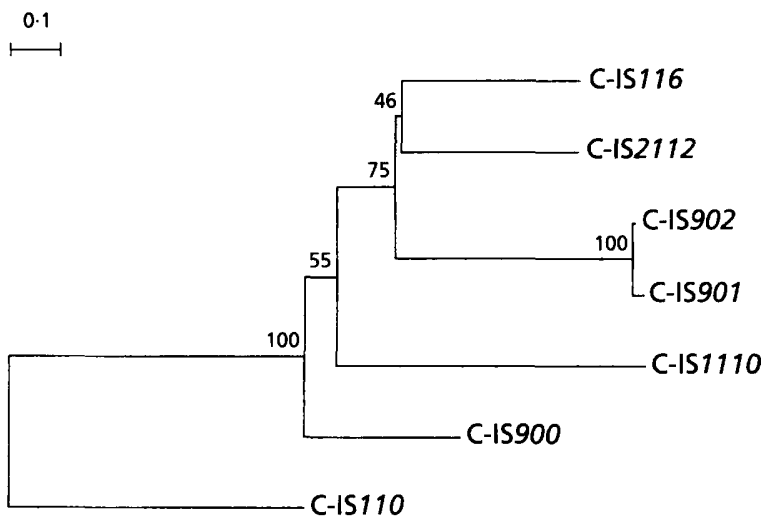

Fig. 4. Phylograms of IS110 family transposases obtained by the neighbour-joining approach. Trees were constructed with the TREECON program. (a) N-terminal parts of transposase genes; (b) C-terminal parts. Bootstrap values (\%) are indicated at the nodes. The scale bars represent $0 \cdot 1$ substitution per site. The IS110 transposase was used as the outgroup (similar phylogenies were obtained when parsimony analysis of the same data was done).

DXXDA motif in region 1 is one of the most conserved features of the reverse transcriptases (Xiong \& Eickbush, 1988).

It was noticed that when different IS110 family transposases were aligned, the extent of homology differed in the $\mathrm{N}$ - and C-terminal halves of some proteins (Fig. 3). A phylogenetic analysis of the alignment of amino acid sequences was performed. Two sets of data were analysed: an alignment of the $\mathrm{N}$-terminal parts of the transposases corresponding to residues $1-200$; and of the C-terminal parts corresponding to residues $201-400$ of IS2112 (Fig. 3). This division of the analysed transposases was not based on any functional properties of the corresponding parts, but has been done solely as an approach for investigation of the possibility of recombinational events (Eltis \& Bolin, 1996). The trees obtained by the neighbour-joining approach are presented in Fig. 4(a, b). This analysis confirms that IS2112 is most closely related to IS116 and that its position on the phylogenetic tree is independent of the data set analysed. A distinctly different result was obtained for other members of the IS110 family. Thus, the N-terminal parts of IS900 and IS901 are more closely related than their C-terminal parts. The position of IS1110 on the phylogenetic tree was also dependent on the part of the protein sequence analysed. The most likely explanation for these results is that a recombinational exchange took place in the course of evolution of members of the IS110 family, although different rates of evolution and/or parallel evolution of $\mathrm{N}$ - and C-terminal parts of transposases cannot be excluded. Whichever hypothesis is assumed, it may be concluded that both IS2112 and IS116 comprise a distinct subfamily in the IS110 family of transposable elements.

\section{Analysis of NCIMB 13064 and its derivatives}

R. rhodochrous NCIMB 13064 can undergo spontaneous genomic rearrangements which result in the loss of the haloalkane utilization $\left(\mathrm{Dha}^{+}\right)$phenotype (Kulakova et al., 1995, 1997). Some of the $\mathrm{Dha}^{-}$derivatives (P200, B4) were stable, while others (S9 and P400) reverted to the original $\mathrm{Dha}^{+}$phenotype. In the case of strain S9, integration of the pRTL1 plasmid into the chromosome took place, whereas strain P200 had a deletion of approximately $20 \mathrm{kbp}$ in the pRTL1 plasmid (Kulakova et al., 1995). These mutants were analysed by Southern blotting to determine the possible role of IS2112 in rearrangements of the NCIMB 13064 genome.

Analysis of a $25 \mathrm{kbp}$ region downstream of the haloalkane dehalogenase gene (dhaA) in NCIMB 13064 did not reveal sequences homologous to IS2112. Analysis of the deletion mutant P200 demonstrated the absence of IS2112 sequences. Assuming that the mutation was caused by a single deletion event, both copies of IS 2112 may therefore be localized upstream of the $d h a A$ gene. This means that the $d h a A$ gene is probably not within a typical composite Tn-like structure bordered by IS 2112 sequences. It is notable that either loss or relocation of the IS2112 sequences had occurred in all of the Dha ${ }^{-}$ derivatives analysed (hybridization results are not presented). Loss of both copies of IS2112 was also detected in a derivative (S14-F) which arose spontaneously in the course of laboratory cultivations of NCIMB 13064 and which had retained the $\mathrm{Dha}^{+}$phenotype.

Hybridization experiments showed that one copy of IS 2112 which was found $5 \mathrm{kbp}$ upstream of the $d h a A$ gene was completely lost in strain S9. However, in the revertant strain S92 one copy of IS2112 was found on an $8.7 \mathrm{kbp} \mathrm{BamHI}$ fragment as in NCIMB 13064, while a second copy of IS2112 had appeared on a smaller $2 \mathrm{kbp}$ Bam HI fragment (results are not presented). Partial sequencing of these copies (approx. $300 \mathrm{bp}$ from both ends) did not reveal any differences to the original IS2112.

To analyse the nature of these rearrangements, the DNA sequences surrounding IS2112 in NCIMB 13064 and in the S9 and S92 mutants were obtained using an inverse PCR method. The reactions were conducted using 


\begin{tabular}{|c|c|c|c|}
\hline & & & \\
\hline Is2112 & CATGGTGTCC $\downarrow$ TCCGT $\ldots \ldots \ldots$ CATTGAAAC $\downarrow$ TCGCTT & NCIMB13064 & Fig. 5. Insertion sites and IS ends for the \\
\hline IS2112-81te & CATGGTGTCCTCGCTT & s9 & target site junctions are taken from the \\
\hline IS2I12 & CATTGAAAC $\downarrow T C C G T \ldots \ldots \ldots$ CATTGAAAC $\downarrow$ TCCGTAA & NCIMB13064 & $\begin{array}{l}\text { following sources: IS116 (Leskiw et al., } \\
\text { 1990), IS900 (Green et al., 1989), IS901 }\end{array}$ \\
\hline IS2112 & $\begin{array}{l}\text { САTGCTGTCC } \downarrow \text { TCCGT } \ldots \ldots \ldots \text { CATTGAAAC } \downarrow \text { TCGCTT } \\
\text { CATGGTCGG } \downarrow T C C C T \\
\end{array}$ & NCIMB13065 & $\begin{array}{l}\text { (Kunze et al., 1992), IS902 (Moss et al., } \\
\text { 1992), IS1110 (Hernandez et al., 1994) and } \\
\text { IS2112 (this study). The alignment of the }\end{array}$ \\
\hline IS900 & CATGTGTT $\downarrow$ TCCTT $\ldots \ldots \ldots$ CATTGAGAAT $\downarrow C C C C T T A$ & & $\begin{array}{l}\text { sequences was performed manually. Not all } \\
\text { sequences obtained for IS900, IS901, IS902 }\end{array}$ \\
\hline IS900 & CATGTGGTGT $\downarrow T C C T T \ldots \ldots \ldots$ CATTGAGAAT $\downarrow C T C C T T T$ & & $\begin{array}{l}\text { and } 152112 \text { are presented in this figure. } \\
\text { Vertical arrows indicate junctions between }\end{array}$ \\
\hline IS901 & CATGCGCTGAT $\downarrow$ TCCTT. . & & the insertion sequence and the target site \\
\hline IS902 & CATTTACAGT $\downarrow$ TCCTT $\ldots \ldots \ldots$ CATTGAGAT $\downarrow$ TCCTTT & & $\begin{array}{l}\text { sequences. The nucleotide sequence which } \\
\text { represents an empty insertion site for IS } 2112\end{array}$ \\
\hline CONSENSUS : & CATTGCTCCG $\downarrow$ TCCTT $\ldots \ldots \ldots$ CATTGAGAG $\downarrow$ TCCTTT & & $\begin{array}{l}\text { (S9 strain) is shown. Bases conserved in all } \\
\text { known sequences and the CCT sequence } \\
\text { conserved in all but IS } 2112 \text { are underlined. } \\
\text { The consensus sequence is indicated. }\end{array}$ \\
\hline
\end{tabular}

internal primers for IS2112 and total DNA preparations restricted with BamHI or EcoRI which were subsequently ligated. Analysis of the sequences (approx. $100 \mathrm{bp}$ ) immediately adjacent to IS2112 in strain S9 showed that they were identical to those surrounding the corresponding copy in the parental NCIMB 13064 strain. Sequences (approx. $100 \mathrm{bp}$ ) surrounding both copies of IS2112 in the S92 strain were also obtained and shown to be identical to those present around the two copies of IS2112 in the original NCIMB 13064 strain. These results suggested that one copy of IS2112 was precisely deleted in strain $\mathrm{S} 9$, but was transposed to the same site in the revertant strain $\mathrm{S} 92$ as a result of a transposition of the remaining copy of IS2112. However, the results do not definitely prove replicative transposition of IS2112 and further experiments are needed to elucidate the transposition mechanism. The new fragment on which a copy of IS2112 was found in the revertant $S 92$ probably originated from an unrelated genomic rearrangement in the adjacent region.

\section{Analysis of IS2112 junctions with target sites}

The junctions of IS2112 with the target sites were analysed on the basis of the two sequenced copies of this element from NCIMB 13064, one copy from NCIMB 13065 and also the empty integration site detected in strain S9. To obtain the sequence of the latter, PCR primers were used which anneal in the regions adjacent to the ends of the corresponding copy of IS2112 and the resulting PCR fragment ( $150 \mathrm{bp}$ ) obtained using S9 DNA was analysed. The sequences for the IS2112 junctions with target sites are presented in Fig. 5 .

The relationship between IS900 and IS elements related to it is clearly pronounced when their ends and targetjunction sites are compared (Fig. 5). None of these elements has terminal inverted repeats and duplication of the target site also does not occur, with the exception of IS1110, which seems to duplicate a target sequence of 5 bp (TCCTT) (Hernandez et al., 1994). It is also worth noting that a precise distinction between the IS sequence and target sequences was not possible in all cases.
Although IS2112 generally conformed with all of the features typical of these elements (Hernandez et al., 1994), some important differences in its ends and target site were observed (Fig. 5). The sequences CAT and CCT were considered the most typical features of the target sites and ends of the IS900 and related elements. A distance of six to nine nucleotides between these sequences is also conserved in all of the members of the IS110 family studied (Moss et al., 1992). The CAT sequence located six to seven nucleotides from the insertion site was found near all three IS2112 sites (two in NCIMB 13064 and one in the NCIMB 13065 strain). However, no CCT sequences were present within 10 nucleotides of the target site. The CCT sequence at the $5^{\prime}$ end of IS2112 was substituted by CGT, whereas CAT at the $3^{\prime}$ end was conserved (Fig. 5). Determination of IS2112 ends allowed the precise size of this element to be calculated as $1415 \mathrm{bp}$.

\section{Occurrence of IS2112 in different strains}

To study the distribution of IS2112, R. rhodochrous NCIMB 13064, several 1-haloalkane-degrading Rhodococcus strains, Rhodococcus strains which are not capable of growth on 1-haloalkanes, and one 1-haloalkane-degrading Pseudomonas strain were analysed by hybridization experiments. A 1050 bp SalI DNA fragment was used as a hybridization probe as described above. Sequences homologous to IS2112 were detected in Rhodococcus strains NCIMB 13064, NCIMB 13065, TB2, Y2, GJ70 and m15-3 (Fig. 2a, b). All these strains are haloalkane degraders. However, two of the haloalkane-degrading strains, Rhodococcus sp. HA1 and ' $P$. pavonaceae' 170 , did not carry sequences homologous to IS2112 (Fig. 2b). None of the other analysed Rhodococcus strains showed hybridization with the IS 2112 probe. The simultaneous presence of IS2112 and the ability to utilize 1 -haloalkanes in a number of $R$ bodococcus strains may be explained by the location of IS2112 and the $d h a A$ gene close to each other on the pRTL1 plasmid. This plasmid was shown to be capable of conjugational transfer (Kulakova et al., 1995) and so 
may be considered responsible for the linked transfer of IS2112 and dhaA to various Rhodococcus strains. Indeed, a plasmid of a similar size as that of pRTL1 $(100 \mathrm{kbp})$ was detected in strain NCIMB 13065.

One copy of IS2112 was found in GJ70, m15-3 and Y2, whereas two copies were present in NCIMB 13064 and TB2 (Fig. 2a, b). Three copies were found in NCIMB 13065 , one of which showed a hybridization band of noticeably lower intensity, suggesting that a sequence with a lower degree of homology to IS2112 was present in this strain (Fig. 2a).

\section{Concluding remarks}

The newly identified insertion element IS2112 belongs to the IS110 family and is one of the first characterized transposable elements of Rhodococcus. IS2112 is most closely related to IS116 and these elements probably comprise a separate subfamily. IS2112 is a member of a group of transposable elements found in actinomycetes which do not possess terminal repeats and in most cases do not duplicate their target sequences upon integration. When considering these differences from the majority of transposable elements, the mechanism of transposition used by this group of transposons is of considerable interest. Although little information is available on their transposition mechanism, it is worth noting, however, that the $S$. coelicolor mini-circle element was initially found in a circular form and as such integrated with up to 100 times higher frequency than when cloned as a linear copy (Henderson et al., 1989). Mahillon \& Chandler (1998) communicate that DNA fragments carrying abutted IS900 ends have been detected in vivo. Their appearance was dependent on an intact transposase gene, and their nucleotide sequence was consistent with the formation of a circular form of the element (although it was also consistent with the presence of a head-to-tail dimer).

IS2112 has so far been found only in 1-haloalkanedegrading Rhodococcus strains. Using derivatives of $R$. rhodochrous NCIMB 13064, we were able to show that IS2112 is involved in the genome rearrangements characteristic for this strain and that some of these rearrangements were connected with the expression of the haloalkane dehalogenase gene. However, there is not yet information available which shows a direct link between these rearrangements and the IS2112 transposition.

\section{ACKNOWLEDGEMENTS}

This project was supported by The Queen's University Environmental Science and Technology Research Centre, European Regional Development Fund - Technology Development Programme and by EC Framework IV Environment and Climate grant ENV4-CT95-0086.

\section{REFERENCES}

Bruton, C. L. \& Chater, K. F. (1987). Nucleotide sequence of IS110, an insertion sequence of Streptomyces coelicolor A3(2). Nucleic Acids Res 15, 7053-7065.
Curragh, H., Flynn, O., Larkin, M. J., Stafford, T. M., Hamilton, J. T. G. \& Harper, D. B. (1994). Haloalkane degradation and assimilation by Rhodococcus rhodochrous NCIMB 13064. Microbiology 140, 1433-1442.

Denome, S. A. \& Young, K. D. (1995). Identification and activity of two insertion sequence elements in Rhodococcus sp. strain IGTS8. Gene 161, 33-38.

Eltis, L. D. \& Bolin, J. T. (1996). Evolutionary relationship among extradiol dioxygenases. J Bacteriol 178, 5930-5937.

Felsenstein, J. (1997). PHYLIP (Phylogeny Inference Package), version 3.57 c. Department of Genetics, University of Washington, Seattle.

Finnerty, W. R. (1992). The biology and genetics of the genus Rhodococcus. Annu Rev Microbiol 46, 193-218.

Fulks, K. A., Marrs, C. F., Stevens, S. P. \& Green, M. R. (1990). Sequence analysis of the inversion region containing the pilin genes of Moraxella bovis. J Bacteriol 172, 310-316.

Green, E. P., Tizard, M. L., Moss, M. T., Thompson, J., Winterbourne, D. J., McFadden, J. J. \& Hermon-Taylor, J. (1989). Sequence and characteristics of IS900, an insertion element identified in a human Crohn's disease isolate of Mycobacterium paratuberculosis. Nucleic Acids Res 17, 9063-9073.

Guilhot, C., Gicquel, B., Davies, J. \& Martin, C. (1992). Isolation and analysis of IS6120, a new insertion sequence from Mycobacterium smegmatis. Mol Microbiol 6, 107-113.

Henderson, D. J., Lydiate, D. J. \& Hopwood, D. A. (1989). Structural and functional analysis of the mini-circle, a transposable element of Streptomyces coelicolor A3(2). Mol Microbiol 3, 1307-1318.

Hernandez, P. M., Fomukong, N. G., Hellyer, T., Brown, I. N. \& Dale, J. W. (1994). Characterization of IS1110, a highly mobile genetic element from Mycobacterium avium. Mol Microbiol 12, 717-724.

Jager, W., Schafer, A., Kalinowski, J. \& Puhler, A. (1995). Isolation of insertion elements from Gram-positive Brevibacterium, Corynebacterium and Rbodococcus strains using the Bacillus subtilis $s a c B$ gene as a positive selection marker. FEMS Microbiol Lett 126, $1-6$.

Janssen, D. B., Jager, D. \& Witholt, B. (1987). Degradation of nhaloalkanes and dihaloalkanes by wild-type and mutants of Acinetobacter sp. strain GJ70. Appl Environ Microbiol 49, 673-677.

Keen, N. T., Tamaki, S., Kobayashi, D. \& Trollinger, D. (1988). Improved broad-host-range plasmids for DNA cloning in Gramnegative bacteria. Gene 70, 191-197.

Kulakov, L. A., Larkin, M. J. \& Kulakova, A. N. (1997). Cryptic plasmid pKA22 isolated from naphthalene degrading derivative of Rhodococcus rbodochrous NCIMB13064. Plasmid 38, 61-69.

Kulakov, L. A., Delcroix, V. A., Larkin, M. J., Ksenzenko, V. N. \& Kulakova, A. N. (1998). Cloning of new Rhodococcus extradiol dioxygenase genes and study of their distribution in different Rbodococcus strains. Microbiology 144, 955-963.

Kulakova, A. N., Stafford, T. M., Larkin, M. J. \& Kulakov, L. A. (1995). Plasmid pRTL1 controlling 1-chloroalkane degradation by Rhodococcus rhodochrous NCIMB13064. Plasmid 33, 208217.

Kulakova, A. N., Larkin, M. J. \& Kulakov, L. A. (1997). The plasmid-located haloalkane dehalogenase gene from Rhodococcus rhodochrous NCIMB 13064. Microbiology 143, 109-115.

Kunze, Z. M., Portaels, F. \& McFadden, J. J. (1992). Biologically distinct subtypes of Mycobacterium avium differ in possession of insertion sequence IS901. J Clin Microbiol 30, 2366-2372. 
Leskiw, B. K., Mevarech, M., Barritt, L. S., Jensen, S. E., Henderson, D. J., Hopwood, D. A., Bruton, C. J. \& Chater, K. F. (1990). Discovery of an insertion sequence, IS116, from Streptomyces clavigerus and its relatedness to other transposable elements from actinomycetes. J Gen Microbiol 136, 1251-1258.

Lydiate, D. J., Ikeda, H. \& Hopwood, D. A. (1986). A 2.6 kb DNA sequence of Streptomyces coelicolor A3(2) which functions as a transposable element. Mol Gen Genet 203, 79-88.

Lydiate, D. J., Ashby, A. M., Henderson, D. J., Kieser, H. M. \& Hopwood, D. A. (1989). Physical and genetic characterization of linear copies of the Streptomyces coelicolor mini-circle. J Gen Microbiol 135, 941-955.

Mahillon, J. \& Chandler, M. (1998). Insertion sequences. Microbiol Mol Biol Rev 62, 725-774.

Miller, J. H. (1972). Experiments in Molecular Genetics. Cold Spring Harbor, NY: Cold Spring Harbor Laboratory.

Moss, M. T., Malik, Z. P., Tizard, M. L., Green, E. P., Sanderson, J. D. \& Hermon-Taylor, J. (1992). IS902, an insertion element of the chronic-enteritis-causing Mycobacterium avium subsp. silvaticum. J Gen Microbiol 138, 139-145.

Nagy, I., Schoofs, G., Vanderleyden, J. \& De Mot, R. (1997). Transposition of the IS21-related element IS1415 in Rhodococcus erythropolis. J Bacteriol 179, 4635-4638.

Pearson, W. R. \& Lipman, D. J. (1988). Improved tools for biological sequence comparison. Proc Natl Acad Sci USA 85, 2444-2448.

Rouch, D. A., Byrne, M. E., Kong, Y. C. \& Skurray, R. A. (1987). The aacA-aphD gentamicin and kanamycin resistance determinant of Tn4001 from Staphylococcus aureus: expression and nucleotide sequence analysis. J Gen Microbiol 133, 3039-3052.

Sallis, P. J., Armfield, S. J., Bull, A. T. \& Hardman, D. J. (1990). Isolation and characterization of a haloalkane halidohydrolase from Rhodococcus erythropolis Y2. J Gen Microbiol 136, 115-120.
Sambrook, J., Fritsch, E. F. \& Maniatis, T. (1989). Molecular Cloning: a Laboratory Manual, 2nd edn. Cold Spring Harbor, NY: Cold Spring Harbor Laboratory.

Scholtz, R., Schmuckle, A., Cook, A. M. \& Leisinger, T. (1987). Degradation of eighteen 1-monoalkanes by Arthrobacter sp. strain HA1. J Gen Microbiol 133, 267-274.

Shine, J. \& Dalgarno, L. (1974). The 3'-terminal sequence of Escherichia coli $16 \mathrm{~S}$ ribosomal RNA : complementarity to nonsense triplets and ribosomal binding sites. Proc Natl Acad Sci USA 71, 1342-1346.

Tajima, F. \& Nei, M. (1984). Estimation of evolutionary distance between nucleotide sequences. Mol Biol Evol 1, 269-285.

Thompson, J. D., Higgins, D. G. \& Gibson, T. J. (1994). CLuSTAL w : improving the sensitivity of progressive multiple sequence alignment through sequence weighting, positions-specific gap penalties and weight matrix choice. Nucleic Acids Res 22, 4673-4680.

Van de Peer, Y. \& De Wachter, R. (1994). TREECON for Windows: a software package for the construction and drawing of evolutionary trees for the Microsoft Windows environment. Comput Applic Biosci 10, 569-570.

Verhagen, C., Smit, E., Janssen, D. B. \& van Elsas, J. D. (1995). Bacterial dichloropropene degradation in soil; screening of soils and involvement of plasmids carrying the $d h l A$ gene. Soil Biol Biochem 27, 1547-1557.

Xiong, Y. \& Eickbush, T. H. (1988). Similarity of reverse transcriptase-like sequences of viruses, transposable elements, and mitochondrial introns. Mol Biol Evol 5, 675-690.

Yokota, T., Fuse, H., Omori, T. \& Minoda, Y. (1986). Microbial dehalogenation of haloalkanes mediated by oxygenase or halidohydrolase. Agric Biol Chem 50, 453-460.

Received 12 August 1998; revised 10 November 1998; accepted 25 November 1998. 